\title{
Short tandem repeat profiling: part of an overall strategy for reducing the frequency of cell misidentification
}

\author{
Raymond W. Nims • Greg Sykes • Karin Cottrill • \\ Pranvera Ikonomi $\cdot$ Eugene Elmore
}

Received: 8 June 2010 / Accepted: 13 September 2010 / Published online: 7 October 2010 / Editor: J. Denry Sato

(C) The Author(s) 2010. This article is published with open access at Springerlink.com

\begin{abstract}
The role of cell authentication in biomedical science has received considerable attention, especially within the past decade. This quality control attribute is now beginning to be given the emphasis it deserves by granting agencies and by scientific journals. Short tandem repeat (STR) profiling, one of a few DNA profiling technologies now available, is being proposed for routine identification (authentication) of human cell lines, stem cells, and tissues. The advantage of this technique over methods such as isoenzyme analysis, karyotyping, human leukocyte antigen typing, etc., is that STR profiling can establish identity to the individual level, provided that the appropriate number and types of loci are evaluated. To best employ this technology, a standardized protocol and a data-driven, qualitycontrolled, and publically searchable database will be necessary. This public STR database (currently under development) will enable investigators to rapidly authenticate human-based cultures to the individual from whom
\end{abstract}

\footnotetext{
R. W. Nims

RMC Pharmaceutical Solutions, Inc,

2150 Miller Drive, Suite A,

Longmont, CO 80501, USA

G. Sykes $\cdot$ K. Cottrill $\cdot$ P. Ikonomi

ATCC,

10801 University Blvd.,

Manassas, VA 20110, USA

E. Elmore $(\square)$

Department of Radiation Oncology,

University of California,

Medical Sciences I, B146D,

Irvine, CA 92697, USA

e-mail: eelmore@uci.edu
}

the cells were sourced. Use of similar approaches for non-human animal cells will require developing other suitable loci sets. While implementing STR analysis on a more routine basis should significantly reduce the frequency of cell misidentification, additional technologies may be needed as part of an overall authentication paradigm. For instance, isoenzyme analysis, PCR-based DNA amplification, and sequence-based barcoding methods enable rapid confirmation of a cell line's species of origin while screening against cross-contaminations, especially when the cells present are not recognized by the species-specific STR method. Karyotyping may also be needed as a supporting tool during establishment of an STR database. Finally, good cell culture practices must always remain a major component of any effort to reduce the frequency of cell misidentification.

Keywords Cell line authentication · STR profiling . Isoenzyme analysis $\cdot$ Karyotyping $\cdot$ DNA barcoding

\section{Introduction}

Authors submitting manuscripts to high-impact chemistry journals must specify the methods used to establish the purity of starting material chemicals for synthesis and other key components used during a study. The results of such quality control testing must also be reported, thereby enabling the reader to judge the validity of the work. Why is the most important reagent of many cell culture studiesthe cell line itself-often lacking test requirements to confirm its identity? If the scientific community agrees that some form of identity testing must be done, what methodology or methodologies should be used? What exactly should cell authentication entail? 
For about as long as scientists have used cell cultures in biomedical research, cases of cell line misidentification have emerged. This problem is especially true for continuous cell lines, with the increased probability over time of mislabeling or cross-contaminating one cell type with another. Historically, the primary cross-contaminant (e.g., Gartler 1967; Nelson-Rees et al. 1974) has been HeLa, a human cervical carcinoma cell which, given the opportunity, rapidly outgrows most other cells in culture. In more recent years, cell lines other than HeLa were implicated in numerous misidentification examples. For example, the cell line ECV304 was originally claimed to be a spontaneously transformed human normal endothelial cell line but was later shown to be T24 bladder cancer cells (Dirks et al. 1999). The putative human prostate cancer cell lines TSUPr1 and JCA-1 proved to be T24 bladder cancer cells (van Bokhoven et al. 2001). DNA fingerprinting analysis demonstrated that the NCI/ADR-RES cell line is actually an ovarian tumor cell line (OVCAR-8) rather than a breast cancer cell line (Liscovitch and Ravid 2006). Many other examples have and continue to be published (Gilbert et al. 1990; Boonstra et al. 2010; Capes-Davis et al. 2010).

What is the impact on biomedical research when investigators use an incorrectly identified cell line? If the cell line is a proxy for a more complex animal or human tissue under investigation, how relevant are the results obtained when, for example, a bladder cell line is used to study chemotherapies directed toward prostate cancer? While such questions are difficult to answer, one can assume that much time, money, and resources have been expended in vain due to this issue. Despite these consequences, the problem of cell misidentification does not appear to be going away (Buehring et al. 2004; Berglind et al. 2008). Not only continuous cell lines are at risk; the use of feeder cells for human stem cell propagation and using xenografts for propagating human tumor cells have provided additional opportunities for cross-contamination and misidentification.

Due to the persistent and courageous championship of Roland Nardone (e.g., Nardone et al. 2007), John Masters (Masters et al. 2001), and others, granting agencies such as the NIH are now beginning to stress the importance of cell authentication (e.g., National Institutes of Health 2007). In addition, scientific journals, such as International Journal of Cancer, Cell Biochemistry and Biophysics, In Vitro Cellular and Developmental Biology-Animal, and the journals of the American Association for Cancer Research are beginning to require the authors to address cell authentication within submitted manuscripts.

In this article, we discuss the role of short tandem repeat (STR) profiling within the greater context of cell authentication strategies for reducing the frequency of human and animal cell misidentification.

\section{Causes of Cell Misidentification}

Many scenarios can potentially lead to cell culture misidentification, and unfortunately, these can play out in even the most prestigious laboratories. They represent either human errors (mislabeling, cross-contamination) or an undesired result of the techniques used (use of feeder layers or xenografting). Such causes may be expressed as a principle of inevitability: that is, given human nature and the nature of cell line maintenance, every laboratory engaged in cell culture research involving the use of more than one cell line may inevitably experience misidentification/cross-contamination. An extension of this principle is that the more frequently a culture needs manipulation (e.g., have its media adjusted or be passaged or subcultured), the greater is the probability of misidentification. Therefore, continuous (immortal; transformed) cultures pose a greater risk than cells with a finite life span, all other factors being equivalent. Failure or refusal of scientists to follow the most basic good cell culture practices (e.g., Masters and Stacey 2007) can only add to the risk of cell misidentification.

The attitude, "I'd just as soon not know," is alive and well in many laboratories. The notion is unfathomable that scientists would knowingly jeopardize their research and careers by not confirming the identity of one of their most valuable resources, their cell cultures. Once unauthenticated cell lines are in use for an extended period and those results are published, "not knowing" prevents the necessity of explaining to the scientific community that the published data may be irrelevant.

In general, human factors furthering the cell line misidentification problem include failing to both appreciate the extent of the problem and take the appropriate preventative measures. Safeguards catching inevitable operator errors and distractions are absent. The specimens are neither checked nor verified.

Perhaps the most straightforward cause of cell line misidentification is the simple mislabeling of a cell culture vessel during routine manipulation (e.g., passage). The culture becomes misidentified as a result. Factors contributing to this type of error might include operator workload, lack of attention, or distractions while handling cell lines.

Cross-contamination of one culture with another and subsequent overgrowth of the culture with the contaminating cell type is another common cause of cell line misidentification. The chances of this occurring are increased by sharing reagents, repeatedly using the same pipette during refeeding operations, and simultaneously working on multiple cultures without adequately isolating one culture from another. Theoretically, a crosscontamination event may result in a spectrum of outcomes, depending upon the growth characteristics of the contam- 
inating cell type relative to those of the parent cell type. In actual practice, the fastest-growing cell type rapidly outgrows the other, leading to a relatively pure culture within four or five passages (Nims et al. 1998).

The intentional establishment of a cocultivation during propagation of human stem cells using a feeder cell derived from another species (e.g., mouse) can contribute to the cross-contamination and overgrowth of the human cells. Normally, feeder cells are rendered, by various means, incapable of proliferating. Occasionally, the feeder cells escape these barriers and proliferate to form mixed cultures, or eventually, cultures are predominated by the feeder cells. Also, cultured cells have the potential to pick up DNA material from "dead" feeder cells. For example, the mantlecell lymphoma cell line, NCEB-1, has acquired multiple murine chromosomes (Camps et al. 2006).

The use of xenografting as a technique for human tumor cell propagation can also lead to cell line crosscontamination and misidentification. In this case, the cell line recovered from the xenograft may occasionally turn out to consist of or include host animal cells rather than a pure culture of the human cells originally grafted (Pathak et al. 1999). In fact, when tissues are xenografted into a host animal, the blood vessels undergo anastomosis to form a hybrid blood vessel (Murry et al. 1994; Chen et al. 2009). Cell lines isolated from xenografts would therefore be prone to cross-contamination.

\section{Good Cell Culture Practices}

To prevent cell line cross-contamination, certain good cell culture practices are absolutely critical. These include the admonitions to (1) manipulate only one type of cell at a time, (2) fully decontaminate the work station after handling one cell line and before working on a second culture, (3) never enter a reagent (medium, buffer, trypsin, etc.) more than once with the same pipette, (4) dedicate a given medium bottle to one specific cell line instead of sharing it with different cell types, and (5) never share media bottles with others. The chances of mislabeling a culture are also increased when two or more different cell lines are handled at the same time, so following the recommended practice of manipulating only one type of cell at a time should help to prevent culture mislabeling as well. Critical to ensuring culture integrity is the identification and remediation of error-prone cell culture practices that bias towards cross-contamination.

Cell morphology for continuous monolayer cell lines should remain constant over time and passage number. Prior to manipulating such a culture, especially if cells from multiple vessels are to be harvested and pooled, the morphology of the cells within each monolayer should be observed. Cultures showing morphological evidence of cross-contamination should not be used.

Routine observation of culture morphology can be an especially straightforward way of detecting crosscontaminated or mislabeled cultures. In fact, observing foci of altered cell morphology within a monolayer culture may be the first sign of a recent cross-contamination (Nims and Herbstritt 2005). Examples of cross-contaminated human cell cultures in which morphology may be used to distinguish the mixed cell types are shown in Fig. 1 (HeLa and normal, early passage human fibroblasts). With permanent cell lines, morphological differences may not always, however, be sufficient to identify crosscontamination. Figure 2 shows the mixed culture of a complex human hybrid cell line (CGL1) (Stanbridge et al. 1981) and a known misidentified cell line "X," a morphologically similar specimen to emphasize the potentially insidious nature of cross-contamination problematic material. Figure $2 A, C$ shows CGL1 and cell line "X", respectively, as individual cultures. Figure $2 B$ shows a mixed culture of the two cell lines. In this case, the presence of the mixed culture is not readily apparent based on morphology of the cells alone but is indicated by the differential staining with CellTracker ${ }^{\mathrm{TM}}$ dyes. The STR profiles from these cultures are shown in Table 1. The CGL1 hybrid cell line shows both the alleles found in the HeLa cell line and the human fibroblast GM00077 (originating from a male patient) used in the hybridization. Even with the complex STR profile found in CGL1, the profile of the mixed culture, CGL1-"X," can identify a contaminating event (Table 1).

In detecting cross-contamination events involving a species different from the putative specimen, additional technologies to human-specific STR analysis are required. Tables 2 and 3

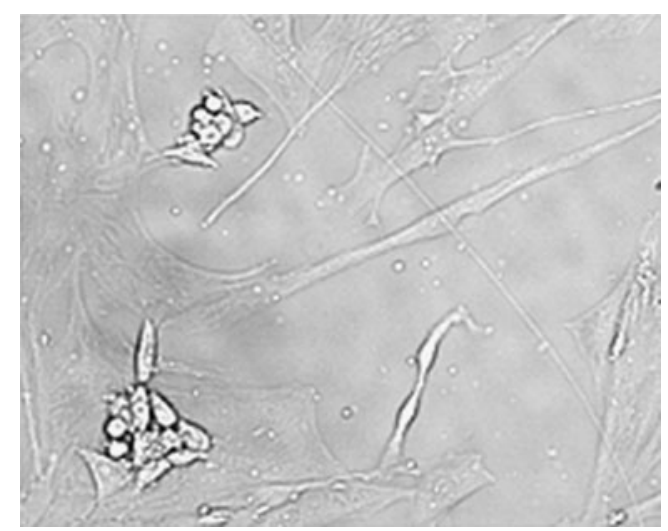

Figure 1. Microscopic examination of a mixed culture of early passage, normal human fibroblasts, and HeLa cell line. The crosscontamination between normal human fibroblasts and HeLa cells (ATCC ${ }^{\circledR}$ CCL-2 ${ }^{\mathrm{TM}}$ ) is easily detected by microscopic examination for morphology: the fibroblasts have an orbital shape while HeLa cells form rounded cell colonies. 

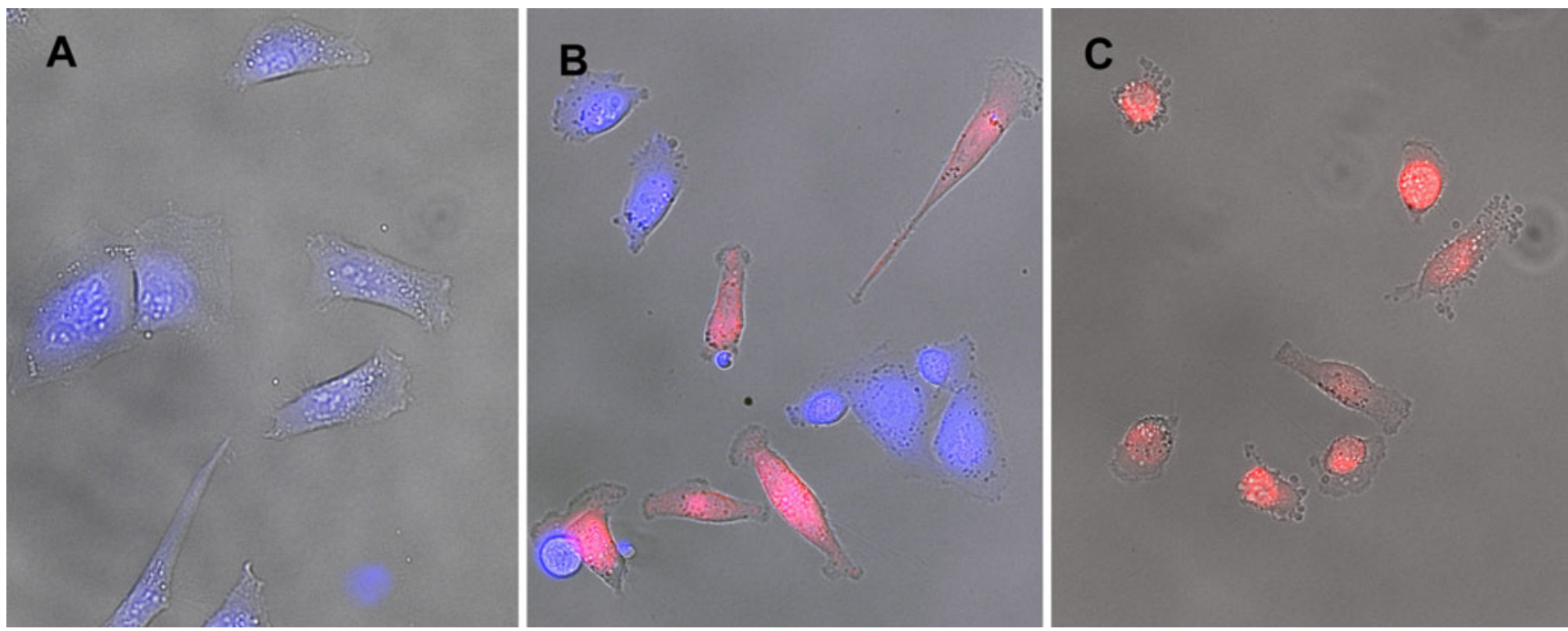

Figure 2. Microscopic examination of a mixed culture between a human hybrid cell line (CGL1) and a known misidentified cell line ("X"). (A) CGL1, a hybrid between HeLa and the human diploid fibroblast, GM00077 (Coriell, Camden, NJ) (Stanbridge et al. 1981) stained with CellTrackerTM Blue CM (C2111, Invitrogen, Carlsbad, CA). CellTracker ${ }^{\mathrm{TM}}$ dyes are cleaved in the cytoplasm to produce a fluorescent color. Once cleaved, the dye is trapped inside the cell. This and the following pictures were taken with $\times 20$ lens using a Nikon Eclipse TE2000-U microscope. Post-capture processing was done with Nikon Elements-AR software. (B) A 50:50 mixed culture of CGL1 and cell line "X," a known misidentified cell line. Similar morphologies prevent easy detection of this particular crosscontamination. A 50:50 mixed culture of CGL1 (stained blue) and cell line "X" stained with CellTracker" Red CMTPX (C34552, Invitrogen) is visually evident only due to the artificial coloration. The "pure" and mixed cultures were cultured overnight to allow cell attachment and recovery. $(C)$ This image shows "pure" cell line " $\mathrm{X}$ " stained with CellTracker ${ }^{\mathrm{TM}}$ Red. illustrate how the presence of mouse DNA in human/ mouse cell mixes remains undetected in human-based STR analysis. Isoenzyme analysis may both confirm the existence and determine the animal species of the contaminant (Nims and Herbstritt 2005). Another more sensitive technology serving this purpose is DNA amplification and barcoding (e.g., Cooper et al. 2007). Applied to the same human/mouse mixes, Table 2 demonstrates how the polymerase chain reaction (PCR)-based species identification assay reveals the previously undetected mouse material. Furthermore, this experiment shows that human material is detectable even at the 1:100 dilution, demonstrating the assay's sensitivity.

Mouse or human feeder cells are used to promote growth of feeder-layer-dependent human stem cells. By testing for cross-contamination, the likelihood of contamination with the feeder cells is reduced. Morphology, in and of itself, is an unsuitable marker for stem cell line purity, as these cultures tend to contain multiple characteristics. Dittmar et al. (2010) demonstrated the utility of STR profiling for detecting misidentified stem cells. With increasing emphasis on clinical applications for stem cells, cell authentication

Table 1. STR profiles for the "pure" cell lines and the mixed culture

\begin{tabular}{llllll}
\hline Alleles $^{\mathrm{a}}$ & HeLa & GM00077 & CGL1 & CGL1-Cell line "X” & Cell line "X" \\
\hline D5S818 & 11,12 & 12 & 11,12 & 11,12 & 11,12 \\
D13S317 & $12,13.3$ & 9,12 & $9,12,13.3$ & $9,10,11,12,13.3$ & 10,11 \\
D7S820 & 8,12 & 8,14 & $8,12,14$ & $8,10,12,14$ & 10,12 \\
D16S539 & 9,10 & 11,13 & $9,10,11,13$ & $9,10,11,12,13$ & 12 \\
TH01 & 7 & $6,9.3$ & $6,7,9.3$ & $6,7,9.3$ & X, Y \\
Am & $\mathrm{X}$ & $\mathrm{X}, \mathrm{Y}$ & $\mathrm{X}, \mathrm{Y}$ & $8,10,12$ & 8 \\
TPOX & 8,12 & 8,10 & $8,10,12$ & $8,9,10,11,12,13$ & $11,12,13$ \\
CSF1PO & 9,10 & 8,10 & $8,9,10$ & \\
\hline
\end{tabular}

\footnotetext{
${ }^{\mathrm{a}}$ A detailed description of each allele is presented at the following link: http:/www.cstl.nist.gov/div831/strbase/str_fact.htm
}

${ }^{\mathrm{b}}$ Note the differences between HeLa and CGL1. All the HeLa STR markers are found in the CGL1 cell line. The extra markers reflect the contribution from the diploid fibroblast (GM00077) used in the hybridization. HeLa shows only X chromosome material. CGL1 shows both X and Y chromosome material

c The mixed culture contains each of the STR markers found in the CGL1 and cell line "X" cultures 
Table 2. Human cells (NCIH522 [H522]; ATCC ${ }^{\circledR}$ CRL$\left.5810^{\mathrm{TM}}\right)$, mouse cells (LL/2 (LLC1); ATCC ${ }^{\circledR}$ CRL-1642 ${ }^{\mathrm{TM}}$ ), and various mixes of the two were subjected to both STR profiling and cytochrome oxidase I (COI)-specific PCR amplification

\begin{tabular}{|c|c|c|}
\hline Sample & STR summary results & PCR species and cross-contamination results \\
\hline Human (CRL-5810 $\left.{ }^{\mathrm{TM}}\right)$ & Full profile & Human \\
\hline Mouse (CRL-1642 & Not detected & Mouse \\
\hline $1: 1$ human/mouse & Full profile & Human, mouse \\
\hline $1: 10$ human/mouse & Some stochastic losses & Human, mouse \\
\hline 1:20 human/mouse & Some stochastic losses & Human, mouse \\
\hline 1:50 human/mouse & Some stochastic losses & Human, mouse \\
\hline 1:100 human/mouse & Heavy stochastic losses & Human, mouse \\
\hline 1:500 human/mouse & Heavy stochastic losses & Mouse \\
\hline $1: 1,000$ human/mouse & Not detected & Mouse \\
\hline Water control & Not detected & No species detected \\
\hline
\end{tabular}

and characterization become paramount. Training in this important area should include cell line authentication as part of good laboratory practices for stem cell culture.

Cultures and/or tissues passaged by xenografting have the same risk. Host cells may integrate into the graft to provide the functional support required for growth. Therefore, cultures maintained or established in this manner have a high cross-contamination probability with host cells (Pathak et al. 1999). The only way to rule out the presence of the host cell type is through isoenzyme analysis, DNA amplification, and barcoding or some alternative species identification method on the derived tumor line.

\section{Cell Authentication}

In the recent past, cell line species confirmation was the main authentication approach, primarily performed by karyotyping or immunological techniques. Later, isoenzyme analysis was employed. Isoenzyme analysis has the advantage that it is rapid and simple and can be used both to confirm species of origin and detect cross-contaminating cells if the latter is present at $10 \%$ or greater (Nims et al. 1998). In fact, isoenzyme analysis is currently the primary method employed within the biopharmaceutical industry for animal cell line authentication to satisfy the 1993 FDA guidance, entitled "Points to Consider in the Characterization of Cell Lines Used to Produce Biologicals" (FDA 1993), and the International Conference on Harmonization guidance ICH Q5D, entitled "Quality of Biotechnological Products: Derivation and Characterisation of Cell Substrates Used for Production of Biotechnological/Biological Products" (International Conference on Harmonization 1998).

Authenticating human cells Isoenzyme analysis generally is incapable of resolving different human cell lines, with the exception of the polymorphism for glucose 6-phosphate dehydrogenase which Gartler (1967) exploited in discovering HeLa-contaminated human cell lines. Classical human cell authentication supplements isoenzyme analysis with karyotypic analysis, especially for diploid cell lines.

Table 3. A detailed examination of the STR profiling results shows gradual allelic loss as the mouse DNA increases relative to the human DNA content

\begin{tabular}{|c|c|c|c|c|c|c|c|c|c|}
\hline Sample & D5S818 & D13S317 & D7S820 & D16S539 & vWA & TH01 & AMEL & TPOX & CSF1PO \\
\hline Human (CRL-5810 & 11 & 10 & 9,10 & 12 & 17 & $7,9.3$ & $\mathrm{X}$ & 9,10 & 10 \\
\hline Mouse (CRL-1642'TM) & - & - & - & - & - & - & - & - & - \\
\hline 1:1 Human/mouse & 11 & 10 & 9,10 & 12 & 17 & $7,9.3$ & $\mathrm{X}$ & 9,10 & 10 \\
\hline $1: 10$ human/mouse & 11 & 10 & 9,10 & 12 & 17 & $7,9.3$ & $\mathrm{X}$ & 10 & 10 \\
\hline 1:20 Human/mouse & - & 10 & 10 & 12 & 17 & 9.3 & $\mathrm{X}$ & - & 10 \\
\hline 1:50 Human/mouse & 11 & 10 & 10 & - & 17 & 7 & - & - & - \\
\hline 1:100 Human/mouse & 11 & - & - & 12 & - & - & - & - & - \\
\hline 1:500 Human/mouse & - & - & - & - & - & - & - & - & 10 \\
\hline 1:1,000 Human/mouse & - & - & - & - & - & - & - & - & - \\
\hline Water Control & - & - & - & - & - & - & - & - & - \\
\hline
\end{tabular}

This loss begins at the 1:10 human/mouse mix (profile is missing TPOX allele 9). The 1:20 through 1:100 human/mouse mixes find some alleles lost at a higher human concentration, only to reappear at lower concentrations due to stochastic effects. However, a general trend remains: reduced number of scored alleles as the relative proportion of mouse DNA increases and the proportion of human DNA decreases 
Increasing resolving power previously required more cumbersome techniques, such as HLA typing or chromosomal banding analysis. The more recent molecular diagnostic techniques, namely single-nucleotide polymorphism (SNP) typing and STR profiling, enable human cell authentication to the individual level. These technologies are now considered viable options for standardizing human cell authentication (Masters et al. 2001; Parson et al. 2005; Schweppe et al. 2008; Pakstis et al. 2010). In fact, an international team of scientists is, at this time, preparing a consensus standard on human cell authentication using STR profiling (ATCC 2009; ATCC $^{\circledR}$ SDO Workgroup ASN0002 2010; Barralon et al. 2010).

What is STR profiling? STR profiling is an analytical DNA technique which PCR-amplifies variable microsatellite regions from a genomic DNA template, separates the PCR amplicons on a genetic analyzer, and uses software to analyze the resulting data and compare the data from one specimen to databases housing previously generated STR sets. The technology depends on the simultaneous amplification of multiple stretches of polymorphic DNA within a single vessel. Repetitive DNA sequences with varying numbers of repeats, referred to as STR loci, are amplified using primers with differently colored fluorophores. These amplicons are distinguished by both size and color (see Fig. 3). The value of the STR profile is appreciated when placed into context of the cell culture's history, the profile's similarity to those of derived cell lines, and its uniqueness to unrelated material. This extremely sensitive and reproducible DNA analysis method has been employed since the early 1990s by forensic analysts, eventually resulting in the Federal Bureau of Investigation Laboratory's Combined DNA Index System, launched in 1990 and formally adapted in 1994. STR profiling was chosen for use in the new human cell authentication Standard (ATCC ${ }^{\circledR}$ SDO Workgroup ASN-0002 2010; Barralon et al. 2010) because it enables authentication to the individual level, is rapid and economical, and is amenable to automation. Furthermore, STR data's reproducible nature makes them suitable for a standard reference database. This standard will meet International Standards Organization guidelines for standards development and will be recognized by the American National Standards Institute (ANSI).
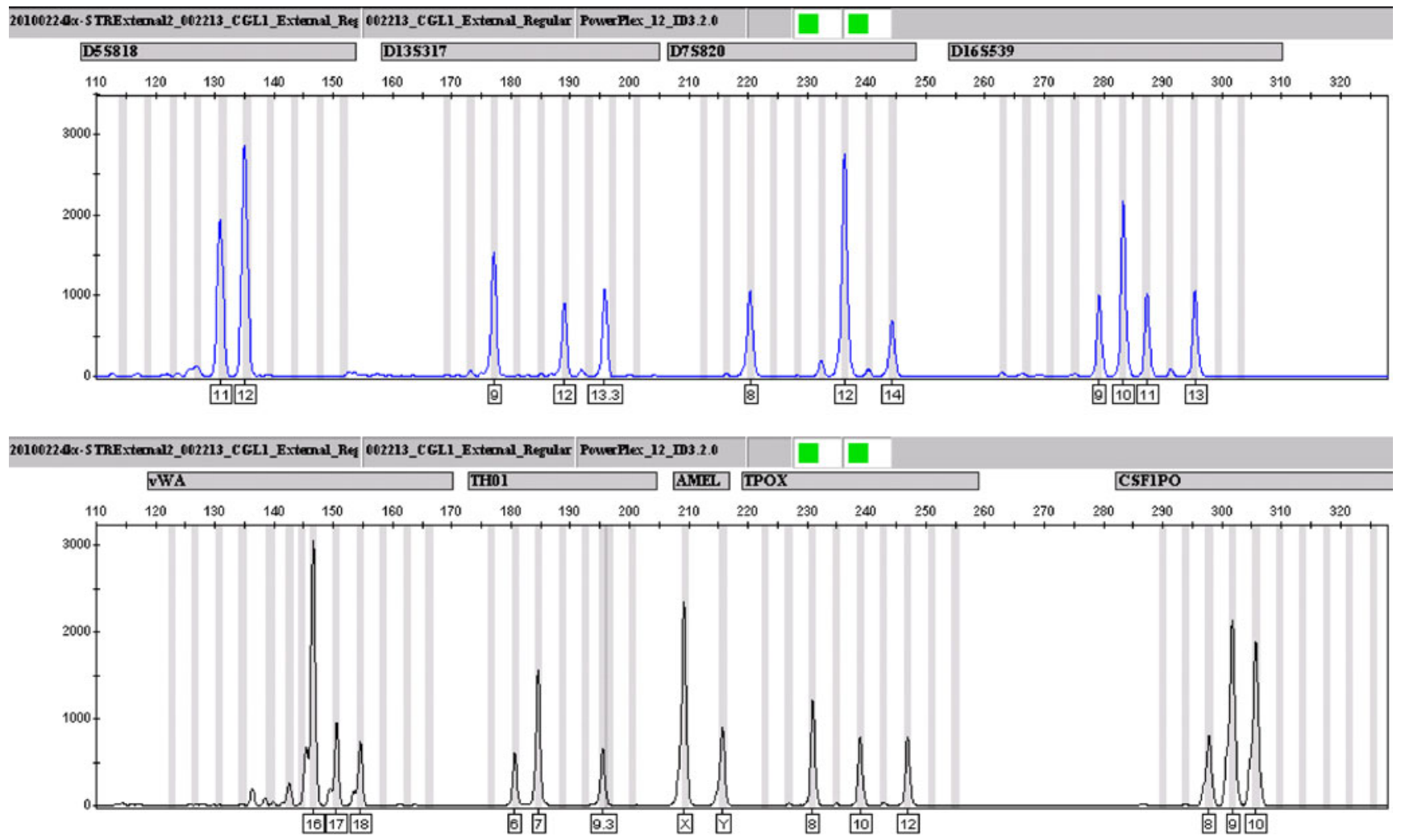

Figure 3. STR profile of CGL1. This STR profile example featuring CGL1 reveals the complexities, such as polyploidy, associated with hybrid cell lines. The STR procedure follows: Cell pellets $\left(\sim 3.5 \times 10^{5}\right.$ cells each) were resuspended in $200 \mu \mathrm{L}$ Qiagen Buffer G2. DNA extraction and purification were conducted on the EZ1 Advanced robotic system (Qiagen, Germantown, MD); readings on the NanoDrop ND-1000 Spectrophotometer (Thermo, Wilmington, DE) pro- duced DNA concentrations. After normalizing the DNA, $1.0 \mu \mathrm{L}$ of sample was amplified using PowerPlex 1.2 (Promega, Madison, WI) in an $8.0-\mu \mathrm{L}$ reaction. An aliquot of the product was mixed with $\mathrm{Hi}-\mathrm{Di}$ formamide [Applied Biosystems Inc. (ABI), Foster City, CA] and Internal Lane Standard (CXR) 60-400 bases (Promega), denatured, and then fractionated on an ABI 3130xl Genetic Analyzer. Resulting data were processed and evaluated using ABI Genemapper v3.2.1. 
The ANSI standard The standard under construction will provide investigators with guidance on applying STR analysis to authenticating human cell lines. Such guidance will include methodological descriptions of DNA sample preparation, stipulate the appropriate numbers and specific loci to be evaluated, and detail the interpretation and quality control of the results. Associated with the standard itself will be the establishment and maintenance of a public STR profile database under the auspices of the National Center for Biotechnology Information.

Proposed paradigm for human cell authentication For newly developed human primary cell cultures and cell lines, including feeder-layer-dependent human stem cells and tumor cells propagated through xenografting, an initial baseline STR profile must be established on the earliest material. Baseline material may include biopsy, frozen tissue, or formalin-fixed paraffin-embedded tissue. For cancer cell lines, the established cell line may express a slightly different STR profile than the heterogeneous tumor. The baseline STR profile for the cell line should also be determined at the time of the initial cryopreservation. Whenever possible to obtain patient specimens, derived from blood or buccal samples, these vouchers powerfully verify the authenticity of the baseline material. For mouse feeder-layer-dependent human stem cell preparations, a DNA amplification and barcoding assay (e.g., Cooper et al. 2007), an isoenzyme analysis assay, or alternative method may need to be performed to demonstrate that there are no cross-contaminating mouse feeder cells in the preparation. To demonstrate the recovered tumor cell line's purity, additional testing may also be necessary in cases involving xenografted material. Laboratories employing continuous cell lines derived from both human and nonhuman animal species will need to monitor crosscontamination using one of the cell species identification methods.

For existing human cell lines, investigators will be encouraged to (1) check the universal database to see if the cell line is represented within the public STR database, (2) ensure that the STR database indicates that this cell line is not misidentified, and (3) perform an STR analysis and compare the results to those within the STR database. Once completed, the ANSI standard will provide the necessary matching criteria (ATCC ${ }^{\circledR}$ SDO Workgroup ASN-0002 2010).

How often should authentication be performed? This is a question which most likely will not be specified explicitly within the standard. Common sense will have to be applied by the investigator. We recommend performing authentication when a cell line is received from an outside source (repository, other investigator). An aliquot could be tested at the time of preparation of the initial frozen cell stock. The culture should have its profile reconfirmed after expanding two or three passages, to check if any contaminants previously below the detection threshold have grown to be more evident (Fig. 4). Cells from the initial frozen stock may then be used for experiments with confidence that the identity is correctly established. The identity of the cell line should be reconfirmed when new cell stocks are prepared. For newly established cultures, a sample of the

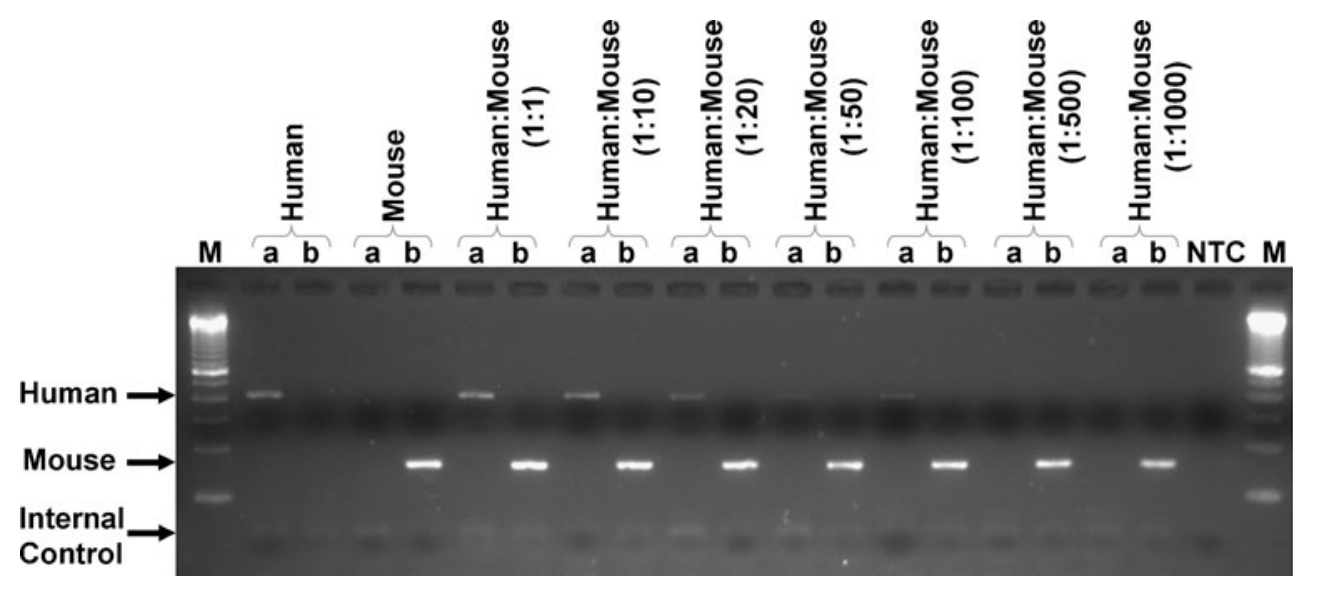

Figure 4. Detection of intraspecies cell mixtures using PCR amplification. Cross-contamination between frequently used cell lines of different species is easily detected using PCR-based species identification assays. Depending on the organism, the speciesspecific primers target either the cytochrome oxidase I or the cytochrome B genes. In this example, mixtures of human (NCIH522 [H522]; ATCC ${ }^{\circledR}$ CRL-5810 ${ }^{\mathrm{TM}}$ ) and mouse cells (LL/2 (LLC1); ATCC $^{\circledR}$ CRL-1642 $\left.{ }^{\mathrm{TM}}\right)$ were created at various ratios and were analyzed via multiplex PCR. The presence of human cells was detected using a set of primers specific for the human COI target (a), while the presence of the mouse contaminant cells was detected using a multiplex PCR targeting 11 non-human species (cat, Chinese hamster, rhesus monkey, horse, cow, African green monkey, rat, goat, dog, New Zealand rabbit, and mouse) (b). Human band 391 bp; mouse band $150 \mathrm{bp}$; internal control $70 \mathrm{bp}$. Abbreviations used: $M$ Invitrogen 100 bp ladder; NTC no template control. These results, together with STR profiling for the cell line mixtures, are also summarized in Table 2. 
culture at the time of the first cryopreservation should be maintained to establish an authentication reference for later passages of the culture. If many different cell lines are employed within a given laboratory, check the identity of the cultures periodically, as such conditions increase the cross-contamination risk. The identity of cell lines used for studies to be published should be confirmed as part of the manuscript submission process.

Animal cell authentication Cell culture species identification is typically conducted through isoenzyme analysis (e.g., Nims and Herbstritt 2005). More recently, DNA amplification and barcoding technologies are gaining increasing acceptance for this purpose (e.g., Cooper et al. 2007). Once the appropriate sets of species-specific loci are established, SNP or STR profiling could also provide a means of determining animal cell line authenticity to the individual level. No consensus as to the role of STR or SNP profiling methodologies for animal cell lines has thus far been reached.

Limitations of SNP and STR profiling for cell authentication The primary drawback of the DNA profiling techniques is an inability to detect interspecies cocultivation or cross-contamination. If a research laboratory has cell lines derived from multiple animal species in culture at any given time, evaluation of those cell lines for species of origin may be required over and above DNA profiling. At present, DNA profiling cannot solely determine the species of mixed cultures (human, mouse, hamster, etc.). To answer that question, laboratories should retain isoenzyme analysis or DNA amplification and barcoding as part of the authentication armament even if STR or SNP profiling become the definitive authentication practices for human and animal cell lines. Karyotyping, while less useful for routine authentication of human and animal cells, may need to be kept as a quality control tool for STR profile data prior to entry into a database.

\section{What role should phenotyping play in cell authentication?}

If a cell displays an expected phenotype, does this mean that identity testing is not required? If a cell does not display the expected phenotype, does this mean the cell is incorrectly identified? The answer to both questions can be no. A cell may display the expected phenotype (e.g., protein secretion, membrane protein status, etc.) and yet be derived from a different source than that expected for the cell (Dittmar et al. 2010). On the other hand, phenotypic expression may change with passage of the cell or with changes in cell environment (growth medium, other culture conditions, etc.), so loss of an expected phenotype or gain of a new phenotype neither confirms nor disputes that the cell is incorrectly identified.
Anticipated impact of implementation of a consensus standard This consensus standard will enable investigators to comply with the evolving expectations of granting agencies and scientific journals regarding cell authentication. The quality control criteria established within the standard and the associated public STR database will ensure an appropriate level of authentication stringency.

Will the standard's implementation significantly reduce the frequency of human cell line misidentification? The answer depends upon a number of factors: (1) the level of compliance with the standard across the biomedical industry; (2) the extent to which granting agencies and scientific journals accept the intent of the standard and require adherence to it, and (3) the willingness of investigators to expend the necessary resources required to adequately train their staff to follow good cell culture practices and to authenticate their cells upon initial receipt and periodically thereafter.

What about animal cells? Animal cell lines are used extensively in biomedical research. Cell culture laboratories typically maintain cells derived from multiple animal species; therefore, a constant threat of cell line crosscontamination and misidentification looms in most cell culture facilities. As is the case for human cells, identity testing is only one part of an overall strategy to reduce cell misidentification frequency. Investigators must accept that the problem exists and take the responsibility for fixing it. A little gentle (or not so gentle) nudging from the scientific journals and granting agencies will help to add the necessary motivation. In the future, some version of STR or SNP profiling may be implemented for non-human animal cells. Until that time, and perhaps even thereafter, isoenzyme analysis and DNA amplification and barcoding will represent important tools for ensuring animal cell line purity.

Acknowledgment The authors thank Trudy Correia (ATCC) for performing the PCR species identification assay.

Open Access This article is distributed under the terms of the Creative Commons Attribution Noncommercial License which permits any noncommercial use, distribution, and reproduction in any medium, provided the original author(s) and source are credited.

\section{References}

ATCC. Update on the development of a consensus standard for the authentication of human cell lines: standardization of STR profiling. ATCC ${ }^{\circledR}$ Standards Development Organization Newsletter 1, 5, 2009. http://atccsdo.org/members/documents/ATCC SDO fall_newsletter_11_05_2009_11_36amCST.pdf

ATCC $^{\circledR}$ SDO Workgroup ASN-0002. Cell line misidentification: the beginning of the end. Nat. Rev. Cancer 10: 441-448; 2010. 
Barralon R.; Bauer S.; Butler J.; Dirks W. G.; Elmore E.; Furtado M.; Kline M. C.; Kohara A.; Los G. V.; Masters J. R. W.; MacLeod R.; Nardone M.; Nardone R. M.; Nims R. W.; Price P. J.; Reid Y. A.; Shewale J.; Steuer A. F.; Storts D. R.; Sykes G.; Thomson J.; Taraporewala Z.; Alston-Roberts C.; Kerrigan L. Recommendation of short tandem repeat profiling for authenticating human cell lines, stem cells, and tissues. In Vitro Cell. Dev. Biol. Anim. 2010. doi:10.1007/s11626-010-9333-z.

Berglind H.; Pawitan Y.; Kato S.; Ishioka C.; Soussi T. Analysis of p53 mutation status in human cancer cell lines. Cancer Biol. Ther. 7: 701-710; 2008.

Boonstra J. J.; van Marion R.; Beer D. G.; Lin L.; Chaves P.; Ribeiro C.; Pereira A. D.; Roque L.; Darnton S. J.; Altorki N. K.; Schrump D. S.; Klimstra D. S.; Tang L. H.; Eshleman J. R.; Alvarez H.; Shimada Y.; van Dekken H.; Tilanus H. W.; Dinjens W. N. M. Verification and unmasking of widely used human esophageal adenocarcinoma cell lines. J. Natl. Cancer Inst. 102: 271-274; 2010.

Buehring G. C.; Eby E. A.; Eby M. J. Cell line cross-contamination: how aware are mammalian cell culturists of the problem and how to monitor it? In Vitro Cell. Dev. Biol. Anim. 40: 211-215; 2004.

Camps J.; Salaverria I.; Garcia M. J.; Prat E.; Beà S.; Pole J. C.; Hernández L.; Del Rey J.; Cigudosa J. C.; Bernués M.; Caldas C.; Colomer D.; Miró R.; Campo E. Genomic imbalances and patterns of karyotypic variability in mantle-cell lymphoma cell lines. Leuk. Res. 30: 923-934; 2006.

Capes-Davis A.; Theodosopoulos G.; Atkin I.; Drexler H. G.; Kohara A.; MacLeod R. A. F.; Masters J. R.; Nakamura Y.; Reid Y. A.; Reddel R. R.; Freshney R. I. Check your cultures! A list of cross-contaminated or misidentified cell lines. Int. J. Cancer 127: 1-8; 2010.

Chen X.; Aledia A. S.; Ghajar C. M.; Griffith C. K.; Putnam A. J.; Hughes C. C. W.; George S. C. Prevascularization of a fibrin-based tissue construct accelerates the formation of functional anastomosis with host vasculature. Tissue Eng. Part A 15: 1363-1371; 2009.

Cooper J. K.; Sykes G.; King S.; Cottrill K.; Ivanova N. V.; Hanner R.; Ikonomi P. Species identification in cell culture: a twopronged molecular approach. In Vitro Cell. Dev. Biol. Anim. 43: 344-351; 2007.

Dirks W. G.; Drexler H. G.; MacLeod R. A. F. ECV304 (endothelial) is really T24 (bladder carcinoma): cell line cross-contamination at source. In Vitro Cell. Dev. Biol. Anim. 35: 558-559; 1999.

Dittmar K. E. J.; Simann M.; Zghoul N.; Schön O.; Meyring W.; Hannig H.; Macke L.; Dirks W. G.; Miller K.; Garritsen H. S. P.; Lindenmaier W. Quality of cell products: authenticity, identity, genomic stability and status of differentiation. Transfus. Med. Hemother. 37: 57-64; 2010.

FDA. Points to consider in the characterization of cell lines used to produce biologicals. CBER, http://www.fda.gov/downloads/Bio logicsBloodVaccines/SafetyAvailability/UCM162863.pdf; 1993.

Gartler S. M. Genetic markers as tracers in cell culture. Natl. Cancer Inst. Monogr. 26: 167-195; 1967.

Gilbert D. A.; Reid Y. A.; Gail M. H.; Pee D.; White C.; Hay R. J.; O'Brien S. J. Application of DNA fingerprints for cell-line individualization. Am. J. Hum. Genet. 47: 499-514; 1990.

International Conference on Harmonisation ICH Q5D. Quality of biotechnological products: derivation and characterisation of cell substrates used for production of biotechnological/biological products. EMEA, http://www.emea.europa.eu/pdfs/human/ich/ 029495en.pdf; 1998.

Liscovitch M.; Ravid D. A case study in misidentification of cancer cell lines: MCF-7/AdrR cells (re-designated NCI/ADR-RES) are derived from OVCAR-8 human ovarian carcinoma cells. Cancer Lett. 245: 350-352; 2006.

Masters J. R.; Stacey G. N. Changing medium and passaging cell lines. Nat. Protoc. 2: 2276-2284; 2007.

Masters J. R.; Thomas J. A.; Daly-Burns B.; Reid Y. A.; Dirks W. G.; Packer P.; Toji L. H.; Ohno T.; Tanabe H.; Arlett C. F.; Kelland L. R.; Harrison M.; Virmani A.; Ward T. H.; Ayres K. L.; Debenham P. G. Short tandem repeat profiling provides an international reference standard for human cell lines. Proc. Natl. Acad. Sci. USA 98: 8012-8017; 2001.

Murry A. G.; Petzelbauer P.; Hughes C. C. W.; Costa J.; Askenase P.; Pober J. S. Human T-cell-mediated destruction of allogeneic microvessels in a severe combined immunodeficient mouse. Proc. Natl. Acad. Sci. USA 91: 9146-9150; 1994.

Nardone R. M.; Masters J. R. W.; Bradlaw J. A.; Jacobsen L. B.; Nims R. W.; Price P. J.; Lewis D.; Stacey G.; McCormick J. J.; Gartler S. M.; Pathak S.; Butler J. M.; Buehring G. C.; Massaro E. J.; Steuer A. F.; Gold M.; Freshney R. I.; Krause D.; O’Brien S. J. An open letter regarding the misidentification and crosscontamination of cell lines: significance and recommendations for correction. July 11, http://cellbank.nibio.go.jp/cellbank/ qualitycontrol/OL7-11-07.pdf; 2007.

National Institutes of Health. Notice regarding authentication of cultured cell lines. Nov. 28, http:/grants.nih.gov/grants/guide/ notice-files/NOT-OD-08-017.html; 2007.

Nelson-Rees W. A.; Flandermeyer R. R.; Hawthorne P. K. Banded marker chromosomes as indicators of intraspecies cellular contamination. Science 184: 1093-1096; 1974.

Nims R. W.; Herbstritt C. J. Cell line authentication using isoenzyme analysis: strategies for accurate speciation and case studies for detection of cell line cross-contamination using a commercial kit. BioPharm Int. 18: 76-82; 2005.

Nims R. W.; Shoemaker A. P.; Bauernschub M. A.; Rec L. J.; Harbell J. W. Sensitivity of isoenzyme analysis for the detection of interspecies cell line cross-contamination. In Vitro Cell. Dev. Biol. Anim. 34: 35-39; 1998.

Pakstis A. J.; Speed W. C.; Fang R.; Hyland F. C. L.; Furtado M. R.; Kidd J. R.; Kidd K. K. SNPs for a universal individual identification panel. Hum. Genet. 127: 315-324; 2010.

Parson W.; Kirchebner R.; Muhlmann R.; Renner K.; Kofler A.; Schmidt S.; Kofler R. Cancer cell line identification by short tandem repeat profiling: powers and limitations. FASEB J. FJ Express 19: 434-436; 2005.

Pathak S.; Nemeth M.; Multani A. S. Human tumor xenografts in nude mice are not always of human origin: a warning signal. Cancer 86: 898-900; 1999.

Schweppe R. E.; Klopper J. P.; Korch C.; Pugazhenthi U.; Benezra M.; Knauf J. A.; Fagin J. A.; Marlow L.; Copland J. A.; Smallridge R. C.; Haugen B. R. DNA profiling analysis of 40 human thyroid cancer cell lines reveals cross-contamination resulting in cell line redundancy and misidentification. J. Clin. Endocrinol. Metab. 93: 4331-4341; 2008.

Stanbridge E. J.; Flandermeyer R. R.; Daniels D. W.; Nelson-Rees W. A. Specific chromosome loss associated with the expression of tumorigenicity in human cell hybrids. Somat. Cell. Mol. Genet. 7: 699-712; 1981.

van Bokhoven A.; Varella-Garcia M.; Korch C.; Miller G. J. TSU-Pr1 and JCA-1 cells are derivatives of T24 bladder carcinoma cells and are not of prostatic origin. Cancer Res. 61: 6340-6344; 2001. 